\title{
Data Analytics and Decision-Making in Education: Towards the Educational Data Scientist as a Key Actor in Schools and Higher Education Institutions
}

\author{
Tommaso Agasisti \\ Politecnico di Milano School of Management \\ tommaso.agasisti@polimi.it
}

\author{
Alex J. Bowers \\ Teachers College, Columbia University \\ Bowers@tc.edu
}

\begin{abstract}
:
In this chapter, we outline the importance of data usage for improving policy-making (at the system level), management of educational institutions and pedagogical approaches in the classroom. We illustrate how traditional data analyses are becoming gradually substituted by more sophisticated forms of analytics, and we provide a classification for these recent movements (in particular learning analytics, academic analytics and educational data mining). After having illustrated some examples of recent applications, we warn against potential risks of inadequate analytics in education, and list a number of barriers that impede the widespread application of better data use. As implications, we call for a development of a more robust professional role of data scientists applied to education, with the aim of sustaining and reinforcing a positive datadriven approach to decision making in the educational field.
\end{abstract}

\section{Keywords:}

Data analysis, learning analytics, data-driven decision making, educational management and policy, data scientist

\section{Setting the stage: defining data mining, learning analytics and academic analytics in the educational field}

The use of data for decision-making in educational institutions is neither a new topic nor an unknown practice. Indeed, since a growing awareness dating back to the

\footnotetext{
1 This document is a pre-print of this manuscript, published in the Handbook of Contemporary Education Economics. Recommended Citation:

Agasisti, T., Bowers, A.J. (2017) Data Analytics and DecisionMaking in Education: Towards the Educational Data Scientist as a Key Actor in Schools and Higher Education Institutions. In Johnes, G., Johnes, J., Agasisti, T., López-Torres, L. (Eds.) Handbook of Contemporary Education Economics (p.184-210). Cheltenham, UK: Edward Elgar Publishing. ISBN: 978-178536-906-3 http://www.e-elgar.com/shop/handbook-ofcontemporary-education-economics
}

Agasisti \& Bowers (2017) 1990s, school principals, teachers, parents, stakeholders and policy-makers started looking at quantitative data as an indispensable source for making decisions, formulating diagnoses about strengths and weaknesses of institutions, and assessing the effects of initiatives and policies, etc. (Bowers, 2008; Mandinach, Honey, Light, \& Brunner, 2008; Wayman, 2005; Wayman, Stringfield, \& Yakimowski, 2004). The diffusion of organizations and initiatives such as Education for the Future (http://eff.csuchico.edu) in the USA, or the DELECA Developing Leadership Capacity for data-informed school improvement project (http://www.deleca.org) in Europe, give testimony to a growing attention to the clever, intensive and informed use of data for improving schools' activities and results. The commitment to engage with a stronger use of data became quite widespread across schools, sustained by the evidence that "(...) the use of data can make an enormous difference in school reform efforts, by helping schools see how to improve school processes and student learning" (Bernhardt, 2004; p. 3). On policy grounds, the movement for adopting more evidence-based educational policies and practices (Davies, 1999; Slavin, 2002) stems from the use of high-quality, originally developed data about academic results obtained through specific initiatives. The current debate of the present chapter is focused on the potential of so-called "big data" to transform education (Daniel, 2015; Cope \& Kalantzis, 2016), as it is rapidly doing in several aspects of social life (Gandomi \& Haider, 2015; Schutt \& O'Neil, 2013).

Recently, one of the first developed areas of research that has worked to systematically use the power of quantitative analyses in the field of education has been the field of Educational Data Mining (EDM) (Baker \& Yacef, 2009; Koedinger, D'Mello, McLaughlin, Pardos, \& Rosé, 2015). The baseline idea was quite simple in origin: applying the techniques, methods and approaches of Data Mining and Business Intelligence to another sector, after having experimented with it in business, health care, genetics, etc. In this sense, EDM “(...) seeks to use data repositories to better understand learners and learning, and to develop 
computational approaches that combine data and theory to transform practice to benefit learners" (Romero \& Ventura, 2010, p.601). In such a perspective, the first aim of an analyst who wants to apply data mining to education is to collect raw data about the educational activities and processes (at individual, organizational and the system level) that have no sense if read without a theoretical background as a lens (Bowers, Krumm, Feng, \& Podkul, 2016). Such an effort has been traditionally very strong, because of the way that data are stored in the educational institutions - namely, following administrative rules and procedures, and with little use of technology (Cho \& Wayman, 2015). Things are changing rapidly, and today many schooling datasets are huge, well-classified, readily available, and much diversified (Behrens \& DiCerbo, 2014; Bowers, 2017; Bowers, Shoho, \& Barnett, 2014; Feng, Krumm, Bowers, \& Podkul, 2016; Koedinger et al., 2010). This evolution has been immediately caught by researchers, and applications of sophisticated data miningstyle analyses to those datasets have generated a rich stream of academic papers, reports, and practical applications (Baker \& Inventado, 2014). In a first stage, then, the research aimed at mainly finding important and frequent recurrences and patterns in available data, something that users of this information usually do not pursue (Bienkowski, Feng, \& Means, 2012). However, opportunities offered by developments in statistics, operations research and information and communication technologies (ICT) are today further empowering the potential of data analysis, by moving towards more sophisticated approaches that are classified under the name of "analytics". Using a definition of Chen et al. (2012, p.1174): “(...) Data analytics refers to the BI\&A (Business Intelligence \& Analytics) technologies that are grounded mostly in data mining and statistical analysis. As mentioned previously, most of these techniques rely on the mature commercial technologies (...)”. The same movement of analysing in more complex and structured ways a large amount of quantitative information has been a focus also of the public sector as a whole (Yiu, 2012; Agasisti et al., forthcoming), and social services, within which the educational sector is one of many, as well as health care (Raghupathi \& Raghupathi, 2014), social care, etc.

Our contribution is focused on the more diffused uses of analytics in the field of education, among which "Learning Analytics" stands out as the recent main commonly adopted definition and approach (Baker \& Inventado, 2014). As recalled by Ferguson (2012, p. 305), the application of analytics to the field of education can be defined as follows: "Learning Analytics is the

Agasisti \& Bowers (2017) measurement, collection, analysis and reporting of data about learners and their contexts, for purposes of understanding and optimising learning and the environments in which it occurs". In practical words, Learning Analytics (hereafter, LA) embraces the methodological and empirical efforts to collect data about the determinants of the educational (learning) process, to analyse it and understand its determinants (Gašević, Dawson, \& Siemens, 2015). A specific attention of this stream of studies is focused on online learning; the amount of information stored in the knowledge management systems (KMS) that facilitate the interaction between the students and the teachers is helpful for analyses - and it permits going beyond the even larger availability of administrative datasets (Andres, Baker, Siemens, Gašević, \& Spann, in press; Chung, 2014; Dawson, Gašević, Siemens, \& Joksimovic, 2014). In this perspective, the promise of analytics evoked by Siemens (2010) can be more easily satisfied by online learning tools: "Learning analytics is the use of intelligent data, learner-produced data, and analysis models to discover information and social connections, and to predict and advise on learning". It should be stressed here that the growing extensive use of digital learning tools and the wider development of approaches for analysing educational data are an intertwined phenomena. As explained by Siemens (2013; p. 1381) “(...) Through the use of mobile devices, learning management systems (LMS) and social media, a greater portion of the learning process generates digital trails. (...) and data trails offer an opportunity to explore learning from new and multiple angles".

Therefore, as acknowledged by Siemens himself, the EDUCAUSE's Next Generation learning initiative offers a broader and cleaner definition, which is "the use of data and models to predict student progress and performance, and the ability to act on that information". In the last definition, the explicit prevision of the "use" of (analysed and elaborated) information introduces another crucial feature of LA, which is the managerial and policy implication derived from the analysis - that is to say, school principals and policy makers put actions in practice based on their judgments about the results of the analyses (Bienkowski, et al., 2012; Bowers, 2017; Bowers, et al., 2014; Feng, et al., 2016). In such a perspective, scholars involved in LA tend to have a different approach from academic educational scientists that focus solely on the

\footnotetext{
${ }^{2}$ See the citation of this definition in the blog EdTech Digest, May 10, 2012

(link available:

https://edtechdigest.wordpress.com/2012/05/10/learninganalytics-the-future-is-now/)
} 
results of studies (also suggesting implications) as LA researchers tend to show very practical uses of the findings for acting in the real life of school management, teaching practices, or policy decisions to be taken. Seen from an institutional perspective, one general characteristic of educational data analytics (and LA in particular) is that the effort traditionally made by individual teachers or specific groups of teachers, i.e. the use of data for improving educational experiences and results, is now made systematic at the organizational level (Bowers, 2017; Bowers, et al., 2016). In other terms, it is no more the single responsibility of individuals in schools to use quantitative evidence for rethinking and redesigning didactic activities and interventions (Cosner, 2014; FarleyRipple \& Buttram, 2015; Schildkamp, Poortman, \& Handelzalts, 2016), as the recent research argues that data analytics is also an institution's task - and, of course, the tools that an institution can use for this aim are much more powerful than those in the hands of volunteer teachers and assistants (Bowers, et al., 2014).

The instruments that can be used for analytics, as well as its objectives (i.e. the specific research and practical questions to be answered), can be substantively different. As a consequence, an attempt is recently emerging for conceptually defining different fields and communities of scholars and practitioners that engage with use of data for educational improvement. We propose here a distinction between three different approaches: educational data mining (EDM), learning analytics (LA) and Academic Analytics (AcAn). Such classification must be intended as provisional, indicative and not prescriptive, and is based on our critical reading of the current state-of-the-art of a literature that is still in its evolution. As a first approximation, the three approaches can be distinguished on the basis of their purpose:

- EDM uses data mining techniques applied to data about the learning process, with the aim of understanding patterns and recurrences (Romero \& Ventura, 2007; Baker \& Inventado, 2014). As defined by Scheuer \& McLaren (2011, p. 1075): “[EDM aims at] developing, researching, and applying computerized methods to detect patterns in large collections of educational data - patterns that would otherwise be hard or impossible to analyse due to the enormous volume of data they exist within".

- LA incorporates many of the models from EDM while focusing on the teaching and learning activity; in this sense, its main aim is to better inform teaching practices (Baker, 2013). Bach (2010) states: "Learning analytics is defined as the use of predictive modelling and other advanced analytic techniques to help target

Agasisti \& Bowers (2017) instructional, curricular and support resources to support the achievement of specific learning goals". A feature of this definition is a major attention to the output of the process, i.e. the achievement goal - LA uses its tools to shed light on those factors that are determinants of learning outputs.

- AcAn, instead, focuses on organizational-level levers that can be activated to change (improve) educational activity and its results. Baepler \& Murdoch (2010) conceive that "Academic analytics combines select institutional data, statistical analysis, and predictive modelling to create intelligence upon which students, instructors, or administrators can change academic behaviour." Beyond the specific context of higher education, this type of focus in K-12 schools and districts has recently also been termed "Organizationlevel Data Analytics" (Bowers, 2017). As stressed by Campbell \& Oblinger (2007, p. 42) in their seminal study on AcAn, this can be "(...) thought as the practice of mining institutional data to produce 'actionable intelligence'". Thus, here the role of school principals and managers - more than teachers - is at the heart of the use of results. In one meaning suggested by Goldstein (2005), Academic Analytics can also be intended as the systematic use of data for generating suggestions aimed at improving the internal efficiency of educational institutions' operations and managerial processes (i.e. personnel management, procurement, etc) $)^{3}$.

On practical grounds, the three approaches are hardly separable, as tools, research questions, policy, and managerial implications tend to be quite similar (as the definitions above suggest). A simplified version of this classification is the one proposed by Siemens \& Long (2011), who defined two broad areas (LA and AcAn) on the basis of their different areas of focus: while LA considers only the learning process, AcAn applies techniques taken by business intelligence to education, with the aim of generating 'value' for the institutions' managers and policy makers. In particular, they suggest a synthesis about how the various types of analytics can differ by level of application (departmental, course-level, institutional, etc.) and can benefit very different groups of interest, such as students, faculty, school managers, etc. This type of work is also analogous to recent writings on the application of "data science" to organizational improvement, where analysts work to translate data into

\footnotetext{
3 For additional details about the role of AcAn for facing administrative and operational concerns (especially in the HE field), see also Fritz (2011) and Goldstein \& Katz (2005).
} 
Table 1. Main differences between educational data mining, learning and academic analytics - a classification

\begin{tabular}{|c|c|c|}
\hline Type of analytics & Level or object of analysis & Who benefits? \\
\hline Educational Data Mining & $\begin{array}{l}\text { Course: learners' profiles } \\
\text { Institution: patterns and recurrences across courses }\end{array}$ & $\begin{array}{l}\text { Researchers and } \\
\text { analysts, faculty, tutors }\end{array}$ \\
\hline \multirow{2}{*}{ Learning Analytics } & $\begin{array}{l}\text { Course: social networks, conceptual development, } \\
\text { discourse analysis, "intelligent curriculum" }\end{array}$ & $\begin{array}{l}\text { Learners, faculty, } \\
\text { tutors }\end{array}$ \\
\hline & $\begin{array}{l}\text { Sub-organization (eg. Department): predictive } \\
\text { modelling, patterns of success/failure }\end{array}$ & Learners, faculty \\
\hline \multirow{3}{*}{ Academic Analytics } & $\begin{array}{l}\text { Institution: learners' profiles, performance of } \\
\text { academics, knowledge flow, institutions' results }\end{array}$ & $\begin{array}{l}\text { Administrators, } \\
\text { funders, marketing }\end{array}$ \\
\hline & $\begin{array}{l}\text { Regional (state/provincial): comparison between } \\
\text { systems (performances, profiles, } \\
\text { observable/administrative differences), benchmarking } \\
\text { of institutions within the system }\end{array}$ & $\begin{array}{l}\text { Funders, } \\
\text { administrators }\end{array}$ \\
\hline & $\begin{array}{l}\text { National and international: comparison between } \\
\text { systems (performances, profiles, } \\
\text { observable/administrative differences), benchmarking } \\
\text { of institutions within the system }\end{array}$ & $\begin{array}{l}\text { Governments, } \\
\text { educational } \\
\text { authorities, } \\
\text { researchers and } \\
\text { analysts }\end{array}$ \\
\hline
\end{tabular}

Source: Authors' elaborations, originally inspired by Romero \& Ventura (2010) and Siemens \& Long (2011).

knowledge and action through data mining and visualization, but also through interfacing with organizational leaders and stakeholders to inform evidence-based decisions (Bowers, 2017; Feng et al., 2016; Schutt \& O'Neil, 2013). Recalling the classification presented above, EDM should not be regarded as an approach in itself, but instead as a method (technique) that can be indifferently used for LA or AcAn purposes. In our own classification and proposal used in this chapter (Table 1), however, EDM must be considered as a distinct area of research and practice, which is conceptually different from the use of analytics techniques, and is helpful solely for preliminary identification of patterns in data, that can be subsequently used after additional analysis (for teaching, in a LA perspective, or for organizational improvements, in a more AcAn-oriented approach).

A common feature of the three approaches is that they share the "loop of data" that is useful for using quantitative information for supporting the decision (Figure 1) (Bowers, et al., 2016; Mandinach, et al., 2008; Marsh, 2012; Schutt \& O'Neil, 2013, Siemens, 2013). More specifically, the first step (Collection \& Acquisition) consists of identifying the relevant datasets that are Agasisti \& Bowers (2017) potentially useful for answering the questions posed by analysts and institutions' managers. Then, through "Storage", datasets are systematically inserted in the availability of official institutions' registers. Experts in these institutions should then revise the structured and unstructured data, with the special purpose of creating new datasets that can be effectively used for subsequent analyses ("Cleaning"). Before starting with the empirical modelling, datasets are subjected to a process of "Integration", which is characterized by the merging of different sources -indeed often the analysis for answering the question(s) necessitates various angles to study the phenomenon under scrutiny. The next step is that of the "Analysis", where statistical, econometric and business intelligence techniques are applied to the relevant datasets, with the aim of detecting interesting patterns and results, and of commenting and interpreting the main findings. After this phase, such results should be synthesized and explained. This is the objective of the step "Representation and Visualization", in which the experts that conducted the analyses should work closely with educational managers to understand the best way to illustrate the results, and to support the awareness of the new knowledge generation within the organization. As discussed in more detail below, 
Figure 1. A data analytics model in education

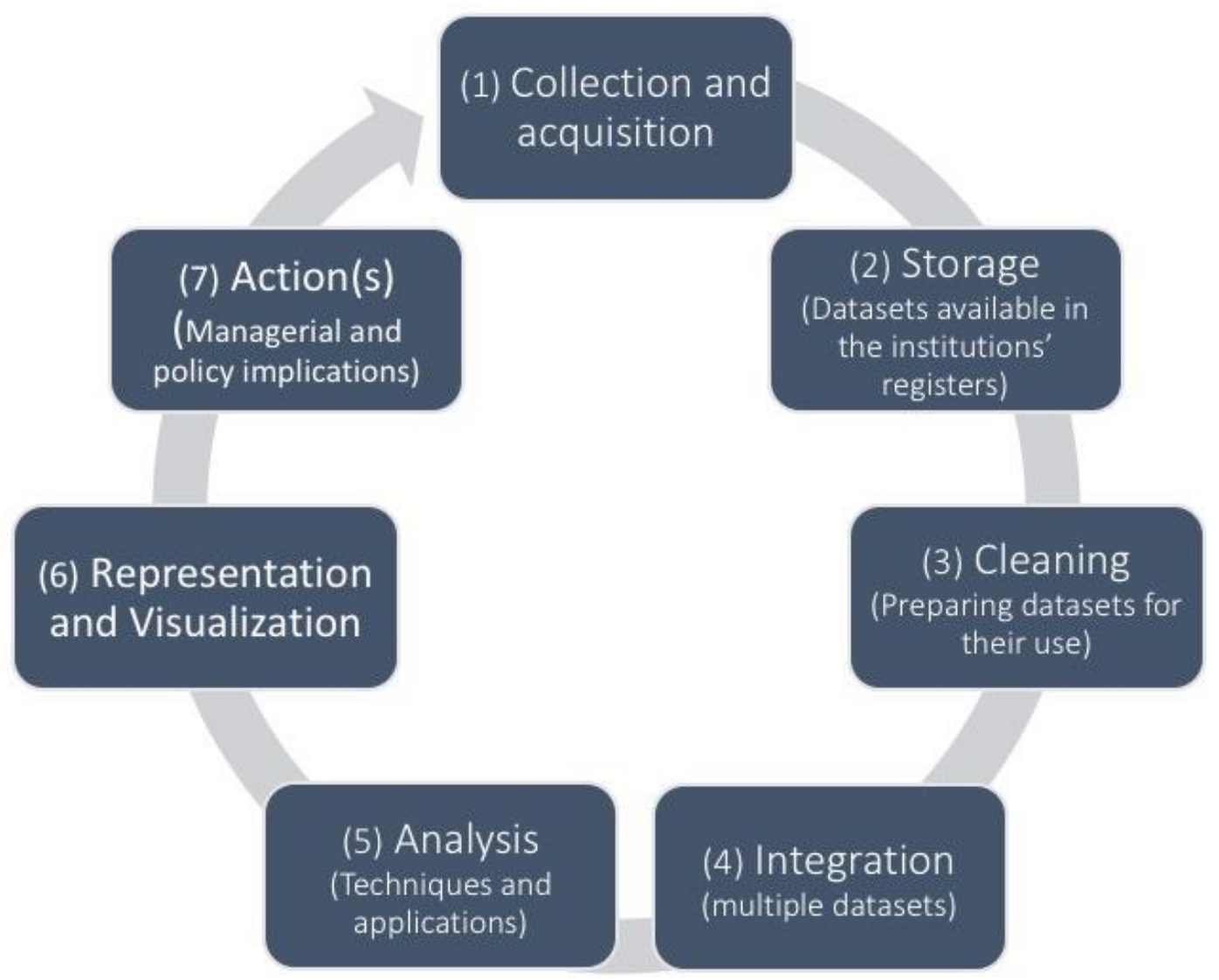

Source: Authors' elaborations, originally inspired by Siemens (2013).

this is where we see the most value for developing the position of the data scientist who can work as a 'bridge' between data analysts and educational managers. Lastly, the evidence from empirical analysis can be used for realizing "Action(s)", that is to say to design remedial interventions, developing new (or modified) curriculum, creating early warning systems and preventing phenomena that harm student achievement, stimulating the development of innovative educational strategies by (groups of) teachers, etc. Of course, the process is recursive, in the sense that new actions should be judged through new data, which in turn require new cleaning, integration, analysis and representation, and so on and so forth.

The debate about the use of analytics in the educational field is empowered by a set of policy and managerial reasons. First of all, the discourse about the efficiency of public spending ("produce more with less"), which is a focus of education systems globally, requires an understanding about the determinants of effective learning, through making use of all the tools and opportunities that Agasisti \& Bowers (2017) new technologies allow. In one sense, the cost of education cannot be considered anymore as granted, and should be instead questioned by its efficiency (i.e. the ability of generating the highest possible level of output) (Ingle \& Cramer, 2013; Levin et al., 2012). In this direction, stagnation in graduation rates for high schools and universities, as well as high levels of dropout from education, in both the US and Europe (Murnane, 2013; de Witte et al., 2013) represent a negative signal for productivity of educational activities (Balfanz, Herzog, \& MacIver, 2007; Bowers, Sprott, \& Taff, 2013; Riehl, 1999; Rumberger \& Palardy, 2005), that then should be further explored with all the available instruments. Current global trends in education accountability then suggest that the policy makers' perspective is to make managers of educational institutions more and more responsible for their results: performance-oriented legislations like the No Child Left Behind (NCLB) Act and Every Student Succeeds Act (ESSA) in the USA, and the recommendations by the European Commission about the efficiency of educational systems (European Commission, 2006) must be read in this light (Leithwood, 2013; Ni, 
Bowers, \& Essewein, 2016). Nevertheless, such policy levers are problematic if knowledge about the learning processes is not advanced. Indeed, this is the area where analytics can be decisive in the future.

As economists of education, education sociologists, and applied data miners and statisticians, we concur with the work of this community of scholars with a particular emphasis on advancing the application of analytics in this domain, towards a closer link between results obtained through analytics and the role of resources, managerial processes, and incentives. Said another way, our goal is to link the evidence from analytics with models of economic behaviour of individuals and organizations through building bridges in the research literature between these domains. In this sense, when possible, we rely on some results from the economics of education literature, to show how they could be integrated with current debates in the communities of learning and academic analytics. In a broader sense, we aim to make our contribution to move the debate from the technicalities behind modelling the learning process towards the theory and empirical. Specifically, we look to focus on econometric analyses of educational processes within the framework of educational production functions (EPFs), on the role of EPFs as a model for studying education used by economists, in the same spirit of Hanushek (1995). Therefore, the way for integrating analytics objectives and the tradition of education and economics studies is in the awareness that "In education, the value of analytics and big data can be found in (1) their role in guiding reform activities in (...) education, and (2) how they can assist educators in improving teaching and learning" (Siemens \& Long, 2011: p. 38), as these are the ultimate goals of research in the field when empirical analysis is used for investigating the determinants of educational results (Coleman et al., 1966).

This chapter aims at proposing a concrete step further in the development of data analytics in education. Our feeling is that, despite the rapid growth of attention towards the role of data and quantitative information for exploring and analysing educational patterns and results, there is still a relevant separation between decision-makers (principals and middle managers at the institution level, politicians at the governmental level) and data analysts and researchers. In a certain sense, the former actors are aware of the great potential that resides in data, but consider their expertise as technically inadequate to use the analyses. The data analysts, on the other side, are satisfied with their empirical (academic) work, and do not enter the practical life and reality of school management and improvement.
The way we see as potentially innovative is to promote the diffusion, within schools, of a new professional profile, that of the educational data scientist, who owns the technical skills to collect, analyse and use quantitative data, and at the same time the managerial and communication skills to interact with decision-makers and managers at the school level to individuate good ways of using the information in the practical way of improving practices and initiatives.

The chapter is organized as follows. In the next section $\S 2$, we review the literature about the use of data for informing policy making $(\$ 2.1)$ and institution-level practices and teaching (\$2.2). Section $\$ 3$ aims at presenting some examples of recent tools used for data analyses and analytics, ranging from traditional statistical explorations to complex instruments of learning and academic analytics. Section $\S 4$ describes the main challenges that can constitute a barrier for the diffusion of analytics in supporting educational decision-making processes. Lastly section $\$ 5$ concludes through the proposal of developing the educational data-scientist as a key profession in schools and universities.

\section{Use of data analyses (and analytics) in the educational arena \\ 2.1 Data use by policy-makers (for implementing, managing and evaluating policy interventions)}

The interest of policy-makers in using quantitative information for guiding policy interventions in education is relatively recent (Jimerson \& Childs, in press), and is based on the awareness that, in the words of Andreas Schleicher (Director of Education at OECD): "Data are crucial to understanding the effect policies have on education systems at a local level" (Schleicher, 2016). The basic idea is that data - when collected and analysed in a proper way - can be helpful for assessing if policies are effective or not, in other words whether they reach the objectives they pursued, and under which conditions this happens.

A specific set of studies argue for the use of international datasets for comparing differences in the educational policies across countries - see Hanushek \& Woessmann (2010). The use of data taken from the most developed assessment of students' achievement in an international fashion is particularly informative for policy-makers, as it allows an understanding of which practices and policies are working in different countries, holding other systemic differences constant. 
Behind this approach, the main assumption is that "institutional structures" (like school autonomy and accountability, competition between schools, and assessment procedures) that are typically invariant at the country level are actually playing a role in shaping systematic differences in students' results across countries. Following this assumption, scholars and analysts have applied analytics to data for suggesting policies that can be adopted in various contexts to improve educational results, by learning from data compared across different contexts/settings. For example, Woessmann (2008) raises the issue of designing output-oriented policies, ranging from early childhood education and schools to higher education, to efficiency improvement and equity of results; Bishop (1997) assesses the effects of national curriculum and testing on student achievement; Brunello \& Checchi (2007) find evidence of detrimental effects of early tracking - i.e. students in countries where early tracking is practised obtain lower test scores, all else equal. A systematic review of policy evaluations that can be conducted - with qualitative and quantitative methods taking advantage of international comparative assessments can be found in Strietholt et al. (2014). Economists, sociologists, and educational scientists moreover, have illustrated the power of data to inform policy-makers about the effects and prospective results of interventions at country level. There are several examples of studies that empirically assess the educational outputs of policies, through the available administrative datasets or surveys at the country level, and/or extracting country-specific data from the international assessments cited above (see, for example, Woessmann, 2008).

A trend that deserves specific attention is the growing confidence in the evidence-based approach, inspired by different disciplines (such as Medicine), and that consists of conducting rigorous "field experiments" (see Slavin, 2002; Mosteller \& Boruch, 2002). The intention of this approach is to provide even more robust evidence about "what works" in education to improve students' and schools' performance, and this would be suggested as a gold standard to policy-makers before undertaking structural reforms (in a logic of "trial" before systemic application) (Schneider, Carnoy, Kilpatrick, Schmidt, \& Shavelson, 2007). Honig \& Coburn (2007) show that policy officers in a United States school district central office read empirical evidence-based analyses, but the interpretation of results as well as the actual use is shaped by the background and characteristics of the officers. Additionally, the "hard" information and evidence is complemented by officers using personal and local

Agasisti \& Bowers (2017) knowledge of educational activities and results. These elements remind us that the attitude of using data is not a purely technical one, but requires human interaction and proactivity for securing a meaningful policy-making process (Marsh, 2012). When considering the use of data by academic scholars, therefore, it should be kept in mind that the primary goal of academic research is not necessarily policy advice. As a consequence, there will also be a "gap" between evidence provided by academic research and implemented, subsequent policies - if any (Whitty 2006). Such a gap is normal, and in a certain sense is desirable as it helps in preserving research independence and ensuring the work is not influenced by policy-making.

A completely different story comes out when considering the influence that think-tanks, foundations or institutional entities exert on politicians and policy-makers by working with educational data. In Europe, for instance, two networks funded by the European Commission (European Expert Network on Economics of Education - EENEE, and Network of Experts on Social Aspects of Education and Training - NESET) are responsible for writing Reports for the Commission, that then go on to influence its official communications. OECD diffuses concise notes with policy suggestions based on data analyses of its Program for International Student Assessment (PISA), named Pisa in Focus. In the US, various institutions issue Reports that talk directly to policy actors, and aim at influencing their subsequent actions - see, for instance, the Reports from Brookings Institutions (e.g., Dynarski, 2016), Friedman Foundation for Educational Choice (Forster, 2016) and Cato Institute (Bedrick et al., 2016). All in all, the explicit aim of these Reports and activities is to stimulate policy debates and sustain political ideas; and policy-makers can selectively consider the results coming out from these studies to justify their positions, or to challenge political ideas sustained by their opponents. This is also a use of data that should be considered; and this attitude is important to be part of actors' awareness - i.e. if data and evidence are presented clearly (and systematically) to policy actors, they reinforce their intentions with the "power of data" - on the complex nexus between data and governing educational systems and policies (see crucial debates in Grek \& Ozga (2009) and Borer \& Lawn (2013)).

\subsection{Data use by the managers (for managerial purposes) and by the teachers (for purposes of improving teaching effectiveness)}

Across the research literature on leadership and data use, much of the research has focused on data-driven decision making by leaders in elementary, middle and secondary 
schools (Bowers et al., 2014; Cosner, 2014; Marsh \& Farrell, 2015; Schildkamp, Karbautzki, \& Vanhoof, 2014; Schildkamp, Poortman, Luyten, \& Ebbeler, in press; Yoon, in press). In this literature, researchers work to understand the role of data in the everyday work of teachers and school principals, with a focus on the role of leaders to set the stage for productive data use. In their review of the relevant literature, Bouwma-Gearhart \& Collins (2015) show how the educational institutions of all grades in both Europe and US are subjected to a greater emphasis on the "culture of evidence", where the use of data can be instrumental to orient interventions. In this vein, the role of quantitative information and evaluation is becoming more and more critical. Reviews of studies about how institutions use data present two types of challenges: (i) organizational (how decision-makers and data producers are linked; which processes and incentives are established for facilitating data use, etc.) and (ii) technical (that deal with data integrity, validity, timeliness, etc.). On the practice side, recommendations stem from normative case studies of data use in practice, focusing on modified PlanDo-Study-Act improvement cycles, and concrete action steps that leaders and teachers can take to use data as a means to build capacity through honest and trusting dialogue with and between teachers (Bambrick-Santoyo, 2010; Boudett et al., 2013; Piety, 2013). Much of this work is focused on helping school practitioners move from a culture of high inference and low evidence, to high evidence with low inference (Bowers et al., 2014), with a focus on the purposeful use of data and information feedback cycles (Mandinach, et al., 2006; Marsh, 2012). Indeed, research that delves deeply into the data use culture in schools has shown that successful use of data by management depends on teacher and leader data and assessment literacy (Datnow \& Hubbard, 2015; Demski \& Racherbäumer, 2015; Mandinach \& Gummer, 2013).

However, while the research on data use articulates a logical evidence-based improvement cycle that moves from data, to information to knowledge, action and feedback to inform each step of the cycle (Mandinach et al., 2006; Marsh, 2012), much of this work devotes little attention to the difficult task of turning data into information and knowledge (Bowers, 2017; Bowers et al., 2016 ; 2014). To date, the research as well as the normative training literature for teachers and leaders has a strong focus on "data" that mostly includes aligning teacher interim assessments to state mandated standardized test scores (Bambrick-Santoyo, 2010; Boudett, et al., 2013; Coburn \& Turner, 2011; Farley-Ripple \& Buttram, 2014; Piety, 2013; Turner \& Coburn, 2012). Additionally, analysis mostly focuses on descriptive statistics (Bowers et al., 2014; Rutledge \& Gale Neal, 2013), that can lead to an over emphasis by school leaders on a deluge of bar graphs and tables that serve mostly to disengage teachers from data rather than create informative dialogue (Murray, 2013; Reeves \& Burt, 2006).

To address this issue, recent research at the elementary, middle and secondary school levels has encouraged an increased role for data analytics in school decision making (Bowers 2017; Bowers, et al., 2016). This work has been mainly focused in the U.S., and has articulated a stronger role of leaders in selecting broader definitions of data to help inform decisions (Bernhardt, 2013; Bowers, 2009), building teacher and leader capacity to create stronger data use systems through more valid and informative assessments (Gummer \& Mandinach, 2015; Jacobs et al., 2009; Popham, 2010) and purposeful data collection systems (Wayman, et al., 2015; 2012; 2007). However, missing from much of this research is a discussion of how data are turned into information and knowledge to be used for evidence-based decision-making (Bowers et al., 2014; 2016). As discussed in the introduction to the present chapter, an emerging line of research has suggested that the fields of EDM and LA may help inform data use in schools (Bienkowski et al., 2012; Means et al., 2010). In this work, EDM and LA are categorized under the larger framework of data analytics in schools, as a means to bring a deeper understanding to the data beyond descriptive statistics, in which the data analytics process provides an opportunity to "make visible data that have heretofore gone unseen, unnoticed, and therefore unactionable" (Bienkowski et al., 2012: p. ix).

A last point that is worth illustrating in this section is the potential of technology in enhancing the understanding of the educational processes, and this can in turn be transformed by teachers as information to be used for improving teaching practices and results (for a theoretical and methodological essay on this point, see Laurillard, 2008). In practice, technology can help teachers to become 'action researchers' for their own teaching roles; by tracking the activities done by students in their courses, they can understand more about how students learn (Behrens \& DiCerbo, 2014; Chung, 2014), and can revise their strategies for learning - also experimenting with new mixes of tools, from more traditional lectures to the introduction of videos, forums, blogs, online interactions, etc (Wayman, et al., 2004). It must be clear, here, that the systematic use of automated, collected information may never substitute the role of teachers in understanding which practices and strategies are better for their specific courses, but IT can complement this continuous effort for 
improvement by adding more evidence to the choices to be made (Gašević, Dawson, \& Siemens, 2015). Williamson (2016) emphasizes this new set of opportunities offered by IT, and proposes the expression "digital education governance" where experts in collecting, managing, analysing and visualizing data have the power to influence decisions taken by various actors. Specifically, the author indicates a trend where "digital data-based (...) instruments are employed to perform a constant audit of students' actions" (p. 138).

\section{Tools for data analyses and analytics: some examples of existent experiences}

\subsection{Examples of data analyses and analytics: different tools for different units of study}

In this section, we critically discuss some examples of using data analyses and analytics for improving students' results and success. For the sake of classification, we divide the examples into four categories:

- Use of data analyses and analytics to inform policy-makers about phenomena that are affecting system-level educational results (at territorial, regional and/or national or even international levels);

- School-level information that would help a school principal and middle management to understand the main patterns followed by students who are attending that specific institution;

- Course-specific data, that are useful for instructors, with the aim of receiving timely feedback on activities undertaken by students, the results, and can activate concrete actions for improving results given the features of the course itself;

- Interfaces for managing data about individual students. In this case, the LA tool has the main objective to propose the courses which students should choose or to provide predictions about prospective results based on individual characteristics, previous grades and/or other additional administrative information.

\footnotetext{
${ }^{4}$ In particular, the author illustrates two major experiences. One is the "Learning Curve" developed by The Economist, at system level - i.e. more pertinent to describe the influence at policy level, as among the group of examples in the section 2.1. The second example is the activity realized by Pearson in its research about Digital Data, Analytics and Adaptive Learning for creating data anticipations and forecasts about individual students.
}

Agasisti \& Bowers (2017)
The choice of the experiences contained in this section has been based on two major criteria: (i) the reference to case studies that are published in international, peer-reviewed academic journals, and (ii) the application of experience for some years, as this allows the reporting of existing assessments of these experiences. By no means should these initiatives be considered the "best practices" in the academic and educational world, as they are neither the first implemented, nor the most complete. Nevertheless, these examples are among the most cited in the current, sparse literature that considers the role of data analyses more systematically, and thus we use these examples, to illustrate how the results provided by these tools can be used for managerial purposes.

The examples illustrated in this section are:

- For the analyses of system-level determinants of instructional results:

- PIRLS (Progress in International Reading Literacy Study) and TIMSS (Trends in International Mathematics and Science Study) studies governed by the International Association for the Evaluation of Educational Achievement (IEA), as well as PISA (Programme for International Student Assessment) administered by Organisation for Economic Co-operation and Development (OECD) - with a specific focus on international analyses of the effectiveness of national educational systems.

- A study for developing an early warning system at national level, based on the use of data for Florida public schools (a description is in Koon \& Petscher, 2015).

- As an example of data analyses for supporting school-level interventions, we rely upon the experience developed within the Strategic Data Project at Harvard University (http://sdp.cepr.harvard.edu). In addition to this Project, we present some insights from best practices among British Schools reviewed for a Report written for the UK's Government (Kirkup et al., 2005) 5 .

- For the LA applied to the course level, the tool Course Signal developed by Purdue University, which is based on an algorithm that considers personal characteristics and online activities to provide students with early warning on potential problems with passing their course (Arnold, 2010;

5 Another analogous experience, that can be of interest for readers is that of AltSchools, as described by Horn (2015) 
Arnold \& Pistilli, 2012). Early applications date back to 2003.

- For the interfaces that provide information to single students (and their instructors), the instrument Degree Compass, a course recommendation system trialled at the Austin Peay State University, and then extended to a group of universities and community colleges in Tennessee ${ }^{6}$.

An example of how the data can be used for analyses of educational results at the system-level is the discussion around the important international assessments of student achievement, those conducted by IEA and OECD as defined above. These organizations release official Reports, every time that a new edition of these studies is available (usually every three years), and they form a baseline for policy discussions worldwide about how educational systems should be reformed or restructured to gain improvements in students' experiences and results. The Reports themselves provide practical suggestions in this vein; for instance, the comments contained in the Report about TIMSS 2011 for mathematics indicates that: "Students with the highest mathematics achievement typically attend schools that emphasize academic success, as indicated by rigorous curricular goals, effective teachers, students that desire to do well, and parental support." (IEA, 2012; p. 16). Some academic studies emphasize how politics have been influenced by that attention to these data (see Grek, 2009; Bieber \& Martins, 2011; and Meyer \& Benavot, 2013 among others). Lastly, several scholars conduct secondary analyses on these data, with the aim of exploring a plurality of educational aspects (and characteristics) that are likely to influence students' results - with the specific intention of suggesting practices, reforms and policy interventions ${ }^{7}$.

\footnotetext{
${ }^{6} \mathrm{~A}$ similar example that can be interesting for the reader is the tool "Check My Activity", implemented by the University of Maryland (Fritz, 2010), which consists of a self-service diagnosis of each student's activity within the environment of the LMS supporting teaching at the University, to be compared against the peers' average. The initiative has been launched in 2008. Also, for a wider discussion of the existent dashboard applications that can support learners' learning (in a LA framework), see Verbert et al. (2013).

${ }^{7}$ There is a huge number of studies of this kind; among others, Hanushek \& Woessmann (2010) maybe stand out as a clear example of an attempt to derive theoretical and empirical economic considerations using data analyses with these datasets. But also see these other interesting examples; Woessman \& West (2006) on the role of class size; Agasisti (2013) for the potential effects of competition between schools; Schmidt et al. (2001) on the curriculum structure.
}

Agasisti \& Bowers (2017)
There are several examples of the systematic use of data for assessing students' performance at a national level; virtually all Ministries and agencies that are responsible for standardized tests in single countries create reports in which the results are summarized and noted, by means of quantitative indicators, to stimulate reflections on the policies and interventions that improve academic results ${ }^{8}$. Less frequent are the cases of employing articulated statistical methodologies to analyse those data. In this chapter, we propose one of these cases, which has been prepared for the Institute of Education Sciences (IES) by the Regional Educational Laboratory Southeast (REL-SE). Using data about Florida public school systems, Koon \& Petscher (2015) illustrate how alternative statistical methods can be used to identify students who are likely to struggle in their educational outputs, and how developing an early warning system at the system level may be useful. Specially, the authors employ two approaches: a set of logistic regressions and classification trees (CART). In both cases, a dichotmous variable is used as the output of the educational process, and is based on a standardized test score (SAT-10), where scores at or above the 40th percentile were coded as 1 for "not at risk", and scores below the 40th percentile were coded as 0 for "at risk", and a battery of test scores are used to predict the student falling in one of the two categories. Then the two approaches (logistic regressions and CARTs) are used for estimating whether students "at risk" actually fail to meet the expected educational standard. Although the methods differ in their theoretical and conceptual backgrounds, the results provided are quite similar (indices of classification accuracy were used to assess differences in the results between the approaches). The authors concluded that: "The CART results were found to be comparable with those of logistic regression, with the results of both methods yielding negative predictive power greater than the recommended standard of .90." (p. 19). In light of these similarities, the authors indicate their preference

\footnotetext{
${ }^{8}$ Another example of instruments which are available at system level for supplying quantitative information to parents and relevant stakeholders are the publicly accessible websites, that benchmark information about test scores and other administrative features of single schools/institutions. Instances of this kind are the website MySchool.Edu, administered by the national government of Australia (see Mockler, 2013) or the various privately-run websites in the US context, as for instance Greatshools.org which effects are being studied by Lovenheim $\&$ Walsh (2014). Although we do not describe these specific examples in further detail here, it is important to be aware of the role that such internet-based information providers are playing in affecting data use and analytics in the educational arena.
} 
towards a more extensive use of the CART approach, by providing an interesting explanation on policy grounds that stems from a higher level of clarity of how results are used. In other words, while the tables containing the logistic regressions' main findings are adequate only for technical readers, figures and tables produced from CARTs are easily interpretable also for stakeholders without a specific technical literacy on statistics. This is crucial in the area of data analyses and data-driven decision making. Indeed, the scope of analysts is not only that of developing robust (and often sophisticated) empirical models, but also to present the obtained results in an understandable way for policy-makers (in this case, at state/national level) so that they can be convinced to take actions (Bowers, 2017; Schutt \& O'Neil, 2013). In our view, the area of elaborating methods for making the findings clearer for key political actors is one where the different competencies of analysts must develop, and when the role of economists of education should be questioned in terms of effectiveness.

Turning to the school level, the idea prompted by the Strategic Data Project (SDP) at Harvard University is of particular interest, given the explicit aim of training people with a given mix of competencies to help school decisionmakers (and principals in particular) to make decisions that are informed by evidence and quantitative data (Hallgren, Pickens Jewell, Kamler, Hartog, \& Gothro, 2013). As indicated in the Project's website, "SDP was formed on two fundamental premises: (i) Policy and management decisions can directly influence schools' and teachers' ability to improve student achievement, and (ii) valid and reliable data analysis significantly improves the quality of decision making." ( http://sdp.cepr.harvard.edu) Of specific value is the experience of the fellowship program in that Project, that provides education for developing skills in three main areas: measurement and analysis, leadership/management and effective communication, and research findings in education policy. The Fellows trained in the project then have experience on real cases of use of data, and are invited to write reports summarizing the experience they have in schools with using data for making decisions. For instance, Holt et al. (2015) wrote a Capstone Report about their experience in Rochester schools, in which they described how they use a plurality of analytical methods (simple regressions, Lasso Regressions ${ }^{9}$, CART, etc.) to describe the patterns of students who do not succeed at Grade 3, by systematically using key information about pre-schooling and results at

\footnotetext{
${ }^{9}$ For an understanding of the way in which LASSO regressions do work, see Tibshirani (1996).
}

Agasisti \& Bowers (2017)
Grades 1 and 2. Based on their analysis, school district policy-makers and principals developed a dashboard that can now be used by the teachers in schools to monitor the progress of their students against a predicted pattern of educational results over time.

Kirkup et al. (2005) conducted a study for the National Foundation for Educational Research (NFER), commissioned by the Department for Education and Skills (DfES). The research aims at identifying how British primary and secondary schools use data for improving teaching and learning activities ${ }^{10}$. The main results of the study was that data usage is not useful per se; instead, " $A$ recurrent theme was that data only becomes effective if it stimulates questions about the actual learning that is taking place and how it can be developed further." The wider findings reported by the authors evidence that school leaders are not searching necessarily for a "tool" that helps them in using data, but instead a way of proceeding that can involve different actors at the school level (teachers, middle-management, etc.) in open dialogue about practices that can be adopted for the improving results, and how data can help in assessing the results of these practices.

Course Signal is one of the most famous examples of LA tools presented by academics and practitioners, and discussed in the scientific community. Course Signal is defined by its developers at Purdue University (where it was also used in experimental trials) as an "early intervention solution": in simple words, its main objective is to data mine large amounts of data about students' characteristics and their use of educational facilities to provide real-time feedback to them (see Arnold, 2010; Arnold \& Pistilli, 2012). The target for the intervention is instructors more than students; indeed, the output of the predictions of academic success in a given course is provided to the former, not the latter. The system is based on the estimation (through data mining techniques) of a "risk level" for each student in each course. The algorithm that calculates such risk level is using four groups of variables: (i) current performance (points earned in a course until a precise moment); (ii) effort, that is monitored through the interactions of students in the Learning Management System; (iii) prior academic

\footnotetext{
10 Also on the use of data for school improvement in the UK case, see Demie (2013). Earl \& Katz (2006) debate how school leaders should use data in a more conceptual way; Yang et al. (1999) created a guide for communicating the results to school heads, while Wayman \& Stringfield (2006) claim for data usage to bringing improvements. Marsh et al. (2006) illustrated how data-driven decision making can be beneficial for schools.
} 
performance, through proxies like high school GPA, grades in previous exams, standardized test scores, etc. and (iv) students' characteristics, such as residency, age, and other administrative information. Once the risk-level for the $\mathrm{i}$-th student in the $\mathrm{k}$-th course is produced, this is transmitted to the instructor; he/she at that point can define an intervention plan for critical cases, and such a plan can range from simple e-mail, to a help-desk, to designing individualized remedial lessons for the student. At a higher level of decision-making, results are also used to restructure curricula and the orientation programs. The results obtained in the first application of Course Signal, as indicated by Arnold \& Pistilli (2012) suggest positive effects on retention - the primary goal of the project. Students that attended a class with Course Signal persist at higher rates than their peers who did not attend classes with Course Signal support. When interviewed, both faculty and students report the behavioural effect of knowing data and receiving feedback, respectively, as the key channel through which the tool exerts its effects. Such clues are a crucial feature of data analytics, moving actors of the educational process (teachers, students and principals) through the provision of actionable information.

Degree Compass is a course recommendation system that suggests the best patterns of courses that a higher education student should take to maximize his/her probability of success (see Denley, 2012; 2013; 2014). The system is based on an algorithm, that is not dependent on students' preferences and willingness to take specific courses (as recommendation systems usually are), but instead on grade and enrolment data. By mining all records about students' characteristics, choices of enrolment and grade obtained, the algorithm ranks courses according to the probability that a student with a certain array of features will succeed in passing it. Also, the system designs the best pattern (i.e. the sequence of courses) following the same approach; and it predicts grades that would be obtained in each of the exams. All this information is then transmitted to each student, through a very simplified web-based interface, in which the strength of recommendation of various course combinations is expressed through the assignment of a number of stars (from 1 to 5). In selecting the courses that are more strongly suggested, the algorithm also considers the choices already made by students (especially, the major and previous exams). In this way "(...) the system most strongly recommends those courses which are necessary for a student to graduate, core to the institution's curriculum and their major, and in which the student is expected to succeed academically" (Denley, 2014; p. 64).
An add-on feature of the system is also the software called MyFuture, which provides information about degree pathways and the transition between higher education and the job market, by mining large datasets to obtain predictions about those courses that are more likely to be conducive to student success. Lastly, the characteristics of the system are periodically discussed with faculty, to obtain their suggestions about which elements should be included in the calculations and predictions made by the algorithm; through such interactions, a by-product is also to obtain higher levels of involvement of faculty members in the project.

Some preliminary results obtained with the use of Degree Compass at both Austin Peay State and Tennessee's institutions, as reported by Denley (2014), seem encouraging. On one side, the average grade obtained by students after the implementation of the tool increased substantially (although it is not clear whether this could be due to grade inflation and/or through the steering of students towards 'easier' courses). This benefit for academic performance appears as uniformly distributed across student subpopulations including minorities and socioeconomically disadvantaged students; this is very important because informative gaps for these groups has been among the major motivations for the project. On the other side, the system is very accurate in predicting success - more than $80 \%$ of students who were predicted to pass a given exam, actually did so. Lastly, there is a significant gain in number of credits acquired by students who choose the suggested courses, as compared with their counterparts who did not choose them. Overall, the positive experience with the instrument contributed to its widespread and integrated use into the day-by-day academic planning and monitoring activity at the University. As students and their specific instructors are the main target of the information provided by the tool, one key aspect of the initiative's success resides in the simple usage of the interface for both actors. Future developments of this experience refer to the ability of collecting more granular data about how to best communicate the information to students, and about how it actually influences students' choices (see Denley, 2013). A last point to be illustrated here is the (indirect) positive effect of the initiative on the economic challenges faced by Austin Peay State University (APSU). Indeed, the State of Tennessee introduced a major change in the formula used for funding public colleges, by introducing graduation and success rates - replacing the previous input-based system. Given the substantial positive effect of Degree Compass in increasing passing rates across students, APSU received a substantial increase of institutional funding. This side- 
effect of the introduction of an effective LA tool highlights the potential synergy between the use of information for students' utility and the positive impact on institutional management and performance.

\subsection{Tools for Data Analyses and Analytics: summarizing considerations}

The presentation of the experiences in the previous section highlight a couple of crucial points that are worth particular attention in depicting the state-of-the-art. First, most of the recent experiences of LA and academic analytics are US-based stories. Although there are potentially interesting cases also in Europe (see, for example, Kickmeier-Rust \& Albert, 2013), it is evident that the practical use of tools for leveraging the value of data in education is much more developed in the NorthAmerican context. It is likely that European researchers in various fields (computer science, education, economics, sociology, etc.) will find a significant space to develop and stimulate real-usage of new available techniques and instruments for LA purposes. Therefore, diffusing good practices in formal and informal settings will also help a more systematic approach towards data-driven (evidencebased) decision making in European educational institutions. Second, many of the practical cases cited above are focused on higher education and, overall, on the use of informative dashboards by students and instructors. In our opinion, two developments are desirable here:

- larger amounts of data are becoming available also for primary and secondary education. As a consequence, researchers and practitioners should start developing new types of tools for supporting teachers in clarifying more the educational strategies that they use, and the results that they are able to obtain, by linking various sources of data about the experience of students that may result also in computer-based suggestions for choices in subsequent educational steps and grades;

- most of the potential use of data is still unexplored by the decision-makers (principals, deans, managers, presidents, etc.) who can instead establish and develop a real evidence-based approach for management of educational institutions, orientated towards greater efficiency and student success. Formative initiatives, benchmarking exercises and sharing of positive experiences can be instruments for developing awareness among decision-makers.

The emerging role of LA and AcAn as distinctive fields of exploration and research is providing support for spurring innovation and experiments in the discipline. For instance, Agasisti \& Bowers (2017) data analytics applications in elementary, middle and secondary school research have most recently focused on the issue of early warning systems and indicators (EWS/EWI) for students at-risk of failure in school (Bowers et al., 2013; Mac Iver, 2013). The study by Knowles (2015) reports the case of a Wisconsin early warning indicator data mining study, which is a good example of how statistical modelling can be coupled with big administrative datasets for scaling an early warning system for high school completion to a state-wide longitudinal data system. Our intuition - that is based on cases presented, and on the recent patterns of the literature about the use of data for supporting decision-making in education - is that LA and AcAn are constituting the next step of evolution for the data analyses in the educational context. Although convinced by this dynamic, we are aware of the severe limitations that the use of analytics in education can encounter: the next section is devoted to describing the main issues among them.

\section{Barriers and impediments to the use of analytics in education}

The previous sections have introduced the motivation for a more extensive use of analyses based on quantitative data as improving performance of schools/HEIs (also with the introduction of more aggressive analytics). We next illustrate the potential drawbacks and obstacles that a strong use of evidence-based decision making can experience in the field of education.

The first problem is ethical, and resides in the intrusive use of data that can threaten privacy and the question about how the use of personal data should be limited (the so call 'big brother' risk) (Ifenthaler \& Tracey, 2016; Slade \& Prinsloo, 2013; Spector, 2016). Many tools that can help improve students' performance are based on tracking previous test scores, and this is embedded in normal screening of student results. Therefore, for working in a more effective way (i.e. for being more predictive of future performance) the systems should also triangulate the information with personal students' characteristics. The identification of individual students in the automated algorithms raise serious privacy concerns, even though the analytical tool is built in the students' interest (see a discussion in Fritz, 2011 - presenting the specific case of a tool called Check My Activity).

In addition, the premise of the most recent, sophisticated tools for analytics is that the analysts should be able to collect together a massive amount of quantitative 
information in their models, for coupling them with learning theories and derive practical information to support policy-making, institutional management and pedagogical initiatives. This approach requires use of data for purposes that are often different from the one for which they were collected - i.e. for research and analyses, rather than for administrative tasks. Also, there are general ethical issues surrounding how acceptable it is to collect and utilize personal information for researchers. Indeed, if the models are employed to trace "profiles" of students and instructors (Lawson, Beer, Rossi, Moore, \& Fleming, 2016; Scholes, 2016; Willis, Slade, \& Prinsloo, 2016), unintended consequences can arise - such as the building of automated algorithms to signal potential outcomes (i.e. dropout or ineffective teaching) and/or the definition of desirable learning patterns dependent upon personal characteristics. Overall, these problems underline that it is necessary to develop a series of guidelines that indicate how data analyses and analytics, originally intended for improving students' satisfaction and results, do not result in a set of practices that harm students' and faculty's rights and privacy (see Willis et al., 2013). Williamson (2016) warns against the risk of a presumed "techno-scientific objectivity".

As one potential guideline in this domain, as has been argued recently across the "Open Access Science" domain in general (Fecher \& Friesike, 2014; Masum et al., 2013; Molloy, 2011; Strasser, 2015), and in the machine learning domain specifically (Braun \& Ong, 2014), we concur with recent authors that open access and open research standards must be used in educational processes, especially when machine learning algorithms are used to make high stakes decisions on students, teachers or schooling systems. As generally noted by Molloy (2011, p. 1), "open" in a research and practice context is defined as "The work shall be available as a whole and at no more than a reasonable reproduction cost, preferably downloading via the Internet without charge. The work must also be available in a convenient and modifiable form". While open access data standards may not apply in education, due to issues of student, parent and school privacy (Willis, Slade, \& Prinsloo, 2016), we argue here that open code and open access standards (Stodden, Guo, $\&$ Ma, 2013) must be used when data analytic or machine learning algorithms are used to inform evidence-based improvement cycles in schools, or to the extent that LA algorithms make recommendations for content and instruction for student learning. Fecher and Friesike (2014), describe five schools of thought in the discourse on open access including "The infrastructure school (which is concerned with the technological architecture), the public

Agasisti \& Bowers (2017) school (which is concerned with the accessibility of knowledge creation), the measurement school (which is concerned with alternative impact measurement), the democratic school (which is concerned with access to knowledge) and the pragmatic school (which is concerned with collaborative research)" [italics original] (p.17). Additionally, as a matter of education system efficiency and ethical use of taxpayer resources, while student data should not be open, the algorithms used in schooling organizations should be published under open access standards so that any student, parent, or concerned citizen may examine the code that may recommend decisions on instruction for their children, teachers and schools across their community and context.

A second problem is more technical in nature, and is about the complexity of data and data integration. Since Bernhardt (2004) it has been clear how data analyses require an adequate system of support to organize data and use them properly; her call of extensive and sapient use of DataWareHouses ${ }^{11}$ must be read in this light. The issue is not only related to the informative system supporting data analyses (which, however, is always a major issue for single educational institutions) but also to the quality and scope of available data. To assure that data uses in the analysis effectively capture the phenomena to be evaluated, data and indicators themselves should have demonstrable robustness, clarity, and pertinence. In other words, even when moving from simple data analyses to more sophisticated analytics, the fundamental basic rules about performance indicators still hold, such as reliability, validity, accuracy and accessibility (Popham, 2010). A certain angle of this perspective is related to the problem of data veracity: it is without a doubt that maintaining data accuracy when collecting and integrating millions of data points from various sources is indeed very challenging.

Third, some authors underline how the creation of an adequate platform for classifying, analysing data, and creating support for decision-making is a costly investment (see Goldstein \& Katz, 2005). Williamson (2016) explains

\footnotetext{
11 As indicated by the Business Dictionary online, a Data Warehouse is (...) “(...) a massive database (typically housed on a cluster of servers, or a mini or mainframe computer) serving as a centralized repository of all data generated by all departments and units of a large organization. Advanced data mining software is required to extract meaningful information from a data warehouse".

(see

weblink

at

http://www.businessdictionary.com/definition/datawarehouse.html)
} 
how the implementation of a sophisticated data analytics approach requires the establishment of a socio-technical data infrastructure, composed by experts and data scientists, as well as by modern hardware and software tools; this of course needs substantial investment. The huge impact of fixed costs for these tasks also explains why some big corporations (like Pearson) and important institutions (like OECD) are developing products and services that can be used by institutions and individual stakeholders. In the spirit of learning/academic analytics, such investments should be sustained by the institutional/central level, somehow taking advantage of scale effects. In the next phases of development of academic analytics, therefore, adopters should also be aware of the necessity to present evidence of cost/benefits for these investments. That is to say that the results favoured by analytics (for instance: higher graduation rates, higher grades, more satisfied students, etc.) must be big enough to justify the amount of money currently invested in creating the data infrastructure and expertise behind the work of analyses. Nevertheless, these issues are completely compatible with requirements for open access code. Not only is open access code publication ethical, especially when the research and development is paid for through taxpayer funds; further development is stimulated through the availability of the code globally. This allowed the development communities to work to standardize and share processes, replicate and extend innovations in multiple contexts, and work collaboratively to increase the usefulness and accuracy of data analytic tools.

Fourth and finally, it is necessary to verify whether the various institutions that are interested in developing sophisticated analyses actually have the necessary competences, in terms of technical (analytical) skills of the personnel or, at least, they create conditions for developing them. As indicated by Arnold et al. (2014), such skills deal with some major areas of competencies/abilities: data expertise (understanding how data are collected, stored and can be questioned and discussed), analytics expertise (to develop and validate statistical and operational modelling), evaluation competences (to assess how analytics is used, and which effects it produces) and teachers/learners' support, with the aim of transferring the knowledge created using data to people engaged in the day-by-day educational practice. Recently Bowers (2017) has detailed specifics for training education research professionals in these skills and competencies within higher education schools of education. Among these capacities, a special place is reserved for the ability of communicating the results of the analyses in an effective manner both to upper management and administration as well as broadly to system stakeholders and participants, which is a determinant for being sure that outputs of analyses are used by decision-makers (see section \$2). This is also important for building consensus in the educational community about the utility of diffusing analytics practices and tools. In this perspective, the methodological challenge is difficult: presenting the results without excessive simplification (providing an awareness of the complexities of the learning process) but with enough clarity to make the information understandable, and thus usable.

\section{A way forward: systemic change and the role of educational data scientists}

The objective of introducing a more systematic and substantial way to the daily use of quantitative information in school and university activities requires a decisive shift in the paradigm of operations that should be accompanied by the introduction of new professional figures. Among them, a key actor that we have in mind is the educational data scientist, whose work is to facilitate the communication between three worlds: (i) one of technical experts in data analyses and analytics, (ii) that of decisionmakers at various levels (policy analysts, school principals, institutions' managers) and (iii) the community of teachers, engaged in frontline instruction. The work of the educational data scientist would be extremely delicate, because it necessitates simultaneously the technical capacity for sophisticated data analysis and the sensibility for the specificities of the educational field -typically qualitative. Mirroring the emerging definitions of data science (Schutt \& O'Neil, 2013), especially as applied to education (Bowers 2017; Bowers, et al., 2016), this work involves the data analytics process noted above in which data are first processed, which also then leads to descriptive statistics, but then current data analytic analyses are applied in an effort to understand and articulate significant and useful previously unidentified patterns in the data as the analyst works to communicate this new information to management.

Practically, such an approach implies a different set of skills to be developed for prospective teachers and school heads. Recently, Bowers (2017), in writing about the role of quantitative methods training for school and school system leaders, articulated four different interconnected roles for school system data leadership. First is the practicing administrator, who requires training in how to use data and analytics to solve problems and inform evidence-based improvement cycles. Second, is the 
quantitative analyst, who in a school system focuses on efficient service management analytics, such as course scheduling, budgets, student transportation and costbenefit analysis for new and current initiatives. Third, is the research specialist, who focuses on assessment construction and validation, surveys and program evaluation with an eye towards psychometrics, testing and inferential statistics. And fourth is the district data scientist, who integrates education data mining, LA, technology and instruction as well as design-based research (Coburn et al., 2013) into school system decision making cycles. Currently, there is a lack of training and capacity building in all four roles, as programs such as Harvard University's recent Strategic Data Project (Hallgren et al., 2013) are relatively new. Complete formative experiences of this kind are virtually absent in Europe, although some universities are starting to work on the topic, more on the research and institutional side - see for instance, the investments made by the University of Edinburgh for using $\mathrm{LA}^{12}$, and/or the project SHEILA (Supporting Higher Education Institutes with Learning Analytics $)^{13}$ also developed at that University. All in all, training and developing this new expertise requires an adequate level of commitment and resources; this scope should suggest a way to prioritize funding allocations in the future.

To conclude, our opinion is that the development of the new figure of data scientists should be part of a wider effort to value the potential of data-driven decision making in education (see, in the same direction, Cope \& Kalantzis,

12 As indicated in the university's website (http://www.ed.ac.uk/information-services/learning-

technology/learning-analytics): "The University of Edinburgh has a wide range of activities in the field of learning analytics. As shown in the diagram below, these activities cross many disciplinary, organisational, practice, and research boundaries. Led by the Vice-Principal Digital Education, Centre for Research in Digital Education, School of Informatics, Information Services, Student Systems, and the Institute for Academic Development, activities in learning analytics include University leaders, researchers, and practitioners from support, research, and academic units of the University collaborating on a variety of projects funded through both internal and external sources."

13 From the Project's website (http://www.de.ed.ac.uk/project/supporting-higher-educationintegrate-learning-analytics-sheila): "SHEILA aims to develop a framework that will guide policy development for learning analytics adoption in higher education in Europe at the levels of ministries of higher education, quality assurance bodies, and institutions. It is in close cooperation with the Society of Learning Analytics and the FP7 project LACE”.

Agasisti \& Bowers (2017)
2016). As predicted by MacFayden et al. (2014), the implementation and effective use of analytics at all levels of the organization requires a structural change of culture, as well as a systemic set of modifications in the way in which the various activities are conducted and assessed. In this perspective, there is not a one-size-fits-all solution, and each organization should find the set of data and processes that best fits its objectives and features. In this sense, it is also useless to conduct single steps of change, while a more coordinated group of actions (from data collection, storing, analyses and use for planning and feedback) seems more adequate for institutional purposes.

\section{Recommended Citation:}

Agasisti, T., Bowers, A.J. (2017) Data Analytics and Decision-Making in Education: Towards the Educational Data Scientist as a Key Actor in Schools and Higher Education Institutions. In Johnes, G., Johnes, J., Agasisti, T., López-Torres, L. (Eds.) Handbook of Contemporary Education Economics (p.184-210). Cheltenham, UK: Edward Elgar Publishing. ISBN: 978-1-78536-906-3 http://www.e-elgar.com/shop/handbook-of-contemporaryeducation-economics

\section{REFERENCES:}

Agasisti T., de Witte K. \& Rogge N. (forthcoming). 'Big data and its use in the measurement of public organizations' performance and efficiency: state-of-the-art and perspectives'. Public Policy and Administration.

Agasisti, T. (2013). 'The efficiency of Italian secondary schools and the potential role of competition: a data envelopment analysis using OECD-PISA2006 data'. Education Economics, 21(5), 520-544.

Andres, J. M. L., Baker, R. S., Siemens, G., Gašević, D., \& Spann, C. A. (in press). Replicating 21 Findings on Student Success in Online Learning. Technology, Instruction, Cognition, and Learning.

Arnold, K. E. (2010). 'Signals: Applying Academic Analytics'. EDUCAUSE Quarterly, 33(1), n1.

Arnold, K. E., \& Pistilli, M. D. (2012). 'Course signals at Purdue: using learning analytics to increase student success'. In Proceedings of the 2nd international conference on learning analytics and knowledge (pp. 267270). ACM.

Arnold, K. E., Lynch, G., Huston, D., Wong, L., Jorn, L., \& Olsen, C. W. (2014). 'Building institutional capacities and competencies for systemic learning analytics initiatives'. In Proceedings of the Fourth International Conference on Learning Analytics and Knowledge (pp. 257-260). ACM. 
Bach, C. (2010). 'Learning analytics: Targeting instruction, curricula and student support'. Office of the Provost, Drexel University.

Baepler, P., \& Murdoch, C. J. (2010). 'Academic analytics and data mining in higher education'. International Journal for the Scholarship of Teaching and Learning, 4(2), 17.

Baker, R. S. (2013). 'Learning, Schooling, and Data Analytics'. In M. Murphy, S. Redding \& J. Twyman (Eds.), Handbook on innovations in learning Philadelphia, PA: Center on Innovations in Learning, Temple University; Charlotte, NC: Information Age Publishing.

Baker, R. S., \& Inventado, P. S. (2014). 'Educational data mining and learning analytics'. In J. A. Larusson \& B. White (Eds.), Learning Analytics (pp. 61-75). New York: Springer.

Baker, R. S., \& Yacef, K. (2009). 'The State of Educational Data Mining in 2009: A Review and Future Visions'. Journal of Educational Data Mining, 1(1), 3-16.

Balfanz, R., Herzog, L., \& MacIver, D. J. (2007). 'Preventing student disengagement and keeping students on the graduation path in urban middle-grades schools: Early identification and effective interventions'. Educational Psychologist, 42(4), 223-235.

Bambrick-Santoyo, P. (2010). Driven by Data: A Practical Guide to Improve Instruction. San Francisco, CA: Jossey-Bass.

Bedrick, J., Butcher, J., \& Bolick, C. (2016). 'Taking Credit for Education: How to Fund Education Savings Accounts through Tax Credits', Cato Institute Policy Analysis, \#785.

Behrens, J. T., \& DiCerbo, K. E. (2014). Technological Implications for Assessment Ecosystems: Opportunities for Digital Technology to Advance Assessment. Teachers College Record, 116(11), 1-22.

Bernhardt, V. (2013). Data analysis for continuous school improvement (3 ed.). New York: Routledge.

Bernhardt, V. L. (2004). Data Analysis for Continuous School Improvement (2 ed.). Eye On Education.

Bieber, T., \& Martens, K. (2011). 'The OECD PISA study as a soft power in education? Lessons from Switzerland and the US'. European Journal of Education, 46(1), 101-116.

Bienkowski, M., Feng, M., \& Means, B. (2012). 'Enhancing Teaching and Learning Through Educational Data Mining and Learning Analytics: An Issue Brief'.
Washington, DC: U.S. Department of Education, Office of Educational Technology.

Bishop, J. H. (1997). 'The effect of national standards and curriculum-based exams on achievement'. The American Economic Review, 87(2), 260-264.

Borer, V. L., \& Lawn, M. (2013). 'Governing Education Systems by Shaping Data: from the past to the present, from national to international perspectives'. European Educational Research Journal, 12(1), 48-52.

Boudett, K. P., City, E. A., \& Murnane, R. J. (2013). Data Wise: Revised and Expanded Edition: A Step-by-Step Guide to Using Assessment Results to Improve Teaching and Learning. Revised and Expanded Edition. Cambridge, MA: Harvard Education Press.

Bouwma-Gearhart, J., \& Collins, J. (2015, October). 'What We Know About Data-Driven Decision Making In Higher Education: Informing Educational Policy and Practice'. In Proceedings of International Academic Conferences (No. 2805154). International Institute of Social and Economic Sciences.

Bowers, A. J. (2008). 'Promoting Excellence: Good to great, NYC's district 2, and the case of a high performing school district'. Leadership and Policy in Schools, 7(2), 154-177.

Bowers, A. J. (2009). 'Reconsidering grades as data for decision making: More than just academic knowledge'. Journal of Educational Administration, 47(5), 609-629.

Bowers, A. J. (2017). 'Quantitative Research Methods Training in Education Leadership and Administration Preparation Programs as Disciplined Inquiry for Building School Improvement Capacity. Journal of Research on Leadership Education, 12(1), p.72-96. http://doi.org/10.1177/1942775116659462.

Bowers, A. J., Krumm, A. E., Feng, M., \& Podkul, T. (2016). 'Building a Data Analytics Partnership to Inform School Leadership Evidence-Based Improvement Cycles'. Paper presented at the Annual meeting of the American Educational Research Association, Washington, DC.

Bowers, A. J., Shoho, A. R., \& Barnett, B. G. (2014). 'Considering the Use of Data by School Leaders for Decision Making'. In A. J. Bowers, A. R. Shoho \& B. G. Barnett (Eds.), Using Data in Schools to Inform Leadership and Decision Making (pp. 1-16). Charlotte, NC: Information Age Publishing.

Bowers, A. J., Sprott, R., \& Taff, S. (2013). 'Do we know who will drop out? A review of the predictors of dropping out of high school: Precision, sensitivity and specificity'. The High School Journal, 96(2), 77-100. 
Braun, M. L., \& Ong, C. S. (2014). 'Open Science in Machine Learning'. In V. Stodde, F. Leisch \& R. D. Peng (Eds.), Implementing Reproducible Research (pp. 343365): Chapman and Hall/CRC.

Brunello, G., \& Checchi, D. (2007). 'Does school tracking affect equality of opportunity? New international evidence'. Economic Policy, 22(52), 782-861.

Campbell, J. P., \& Oblinger, D. G. (2007). 'Academic analytics'. EDUCAUSE Review, 42(4), 40-57.

Chen, H., Chiang, R. H., \& Storey, V. C. (2012). 'Business Intelligence and Analytics: From Big Data to Big Impact'. MIS Quarterly, 36(4), 1165-1188.

Cho, V., \& Wayman, J. C. (2015). 'Districts' Efforts for Data Use and Computer Data Systems: The Role of Sensemaking in System Use and Implementation'. Teachers College Record, 116(2), 1-45.

Coburn, C. E., \& Turner, E. O. (2011). 'Research on Data Use: A Framework and Analysis'. Measurement: Interdisciplinary Research and Perspectives, 9(4), 173206.

Coburn, C. E., Penuel, W. R., \& Geil, K. E. (2013). Research-Practice Partnerships: A Strategy for Leveraging Research for Educational Improvement in School Districts. New York, NY: William T. Grant Foundation.

Coleman, J. S. (1966). Equality of educational opportunity. Washington, DC: U.S. Department of Health, Education, and Welfare, Office of Education.

Cope, B., \& Kalantzis, M. (2016). 'Big Data Comes to School'. AERA Open, 2(2), 1-19.

Cosner, S. (2014). 'Strengthening Collaborative Practices in Schools: The Need to Cultivate Development Perspectives and Diagnostic Approaches'. In A. J. Bowers, A. R. Shoho \& B. G. Barnett (Eds.), Using Data in Schools to Inform Leadership and Decision Making. Charlotte, NC: Information Age Publishing.

Chung, G. K. W. K. (2014). Toward the Relational Management of Educational Measurement Data. Teachers College Record, 116(11), 1-16.

Daniel, B. (2015). 'Big Data and analytics in higher education: Opportunities and challenges'. British Journal of Educational Technology, 46(5), 904-920.

Datnow, A., \& Hubbard, L. (2015). 'Teachers' Use of Assessment Data to Inform Instruction: Lessons From the Past and Prospects for the Future'. Teachers College Record, 117(4), 1-26.
Dawson, S., Gašević, D., Siemens, G., \& Joksimovic, S. (2014). 'Current state and future trends: a citation network analysis of the learning analytics field'. Paper presented at the Proceedings of the Fourth International Conference on Learning Analytics And Knowledge, Indianapolis, Indiana, USA.

Davies, P. (1999). 'What is evidence-based education?', British Journal of Educational Studies, 47(2), 108-121.

De Witte, K., Cabus, S., Thyssen, G., Groot, W., \& van den Brink, H. M. (2013). 'A critical review of the literature on school dropout'. Educational Research Review, 10, 1328.

Demie, F. (2013). Using Data to Raise Achievement Good Practice in Schools. Lambeth Research and Statistics Unit.

Demski, D., \& Racherbäumer, K. (2015). 'Principals' Evidence-Based Practice--Findings from German Schools'. International Journal of Educational Management, 29(6), 735-748.

Denley, T. (2012). 'Austin Peay State University: Degree Compass'. In D.G. Oblinger (ed.), Gamer changers: education and information technologies (pp. 263-267), EDUCAUSE.

Denley, T. (2013). 'Degree Compass: A Course Recommendation System'. EDUCAUSE Review Online. http://er.educause.edu/articles/2013/9/degree-compass-acourse-recommendation-system

Denley, T. (2014). 'How predictive analytics and choice architecture can improve student success'. Research \& Practice in Assessment, 9.

Dynarski, M. (2016). 'On negative effects of vouchers'. Brookings Institution. Evidence Speaks Reports, Vol 1, \#18.

Earl, L. M., \& Katz, S. (Eds.). (2006). Leading schools in a data-rich world: Harnessing data for school improvement. Corwin Press.

European Commission. (2016). Communication from the Commission to the Council and to the EU Parliament, 8/9/2006, on efficiency and equity in European education and training systems, $\mathrm{COM}(2006) 481$ final.

Farley-Ripple, E. N., \& Buttram, J. L. (2014). 'Schools' Use of Interim Data: Practices in Classrooms, Teams, and Schools'. In A. J. Bowers, A. R. Shoho \& B. G. Barnett (Eds.), Using Data in Schools to Inform Leadership and Decision Making (pp. 39-66). Charlotte, NC: Information Age Publishing. 
Farley-Ripple, E. N., \& Buttram, J. L. (2015). 'The Development of Capacity for Data Use: The Role of Teacher Networks in an Elementary School'. Teachers College Record, 117(4), 1-34.

Fecher, B., \& Friesike, S. (2014). 'Open Science: One Term, Five Schools of Thought'. In S. Bartling \& S. Friesike (Eds.), Opening Science: The Evolving Guide on How the Internet is Changing Research, Collaboration and Scholarly Publishing (pp. 17-47). Cham: Springer International Publishing.

Feng, M., Krumm, A. E., Bowers, A. J., \& Podkul, T. (2016). 'Elaborating data intensive research methods through researcher-practitioner partnerships'. Paper presented at the Proceedings of the Sixth International Conference on Learning Analytics \& Knowledge, Edinburgh, United Kingdom.

Ferguson, R. (2012). 'Learning analytics: drivers, developments and challenges'. International Journal of Technology Enhanced Learning, 4(5-6), 304-317.

Forster, G. (2009). 'A Win-Win Solution: The Empirical Evidence on How Vouchers Affect Public Schools. School Choice Issues in Depth'. Friedman Foundation for Educational Choice.

Fritz, J. (2010). 'Video Demo of UMBC's" Check My Activity" Tool for Students'. Educause Quarterly, 33(4).

Fritz, J. (2011). 'Classroom walls that talk: Using online course activity data of successful students to raise self-awareness of underperforming peers'. The Internet and Higher Education, 14(2), 89-97.

Gandomi, A., \& Haider, M. (2015). 'Beyond the hype: Big data concepts, methods, and analytics'. International Journal of Information Management, 35(2), 137-144.

Gašević, D., Dawson, S., \& Siemens, G. (2015). 'Let's not forget: Learning analytics are about learning'. TechTrends, 59(1), 64-71.

Goldstein, P. J., \& Katz, R. N. (2005). 'Academic analytics: The uses of management information and technology in higher education', EDUcause.edu.

Grek, S. (2009). 'Governing by numbers: The PISA 'effect' in Europe'. Journal of Education Policy, 24(1), 23-37.

Grek, S., \& Ozga, J. (2009). 'Governing education through data: Scotland, England and the European education policy space'. British Educational Research Journal, 36(6), 937-952.
Gummer, E. S., \& Mandinach, E. (2015). 'Building a Conceptual Framework for Data Literacy'. Teachers College Record, 117(4), 1-22.

Hallgren, K., Pickens Jewell, C., Kamler, C., Hartog, J., \& Gothro, A. (2013). Strategic data project and education pioneers year 1 report: Laying the groundwork for datadriven decision making. Princenton, NJ: Mathematica Policy Research.

Halverson, R. (2010). 'School formative feedback systems'. Peabody Journal of Education, 85(2), 130-146.

Hanushek, E. A. (1995). 'Education production functions'. In International Encyclopedia of Economics of Education, 277-282.

Hanushek, E. A., \& Woessmann, L. (2010). 'The economics of international differences in educational achievement' (No. w15949). National Bureau of Economic Research.

Holt, A., \& Schools, T. P. (2015). Early Elementary On-Track Indicators Leading to Third-Grade Reading Proficiency. SDP Capstone Report.

Honig, M. I., \& Coburn, C. (2007). 'Evidence-based decision making in school district central offices: Toward a policy and research agenda'. Educational Policy.

Horn, M. B. (2015). 'The Rise of AltSchool and Other Micro-schools'. Education Next, 15(3).

IEA (2012). 'TIMSS 2011 International Results in Mathematics - Executive Summary', Chestnut Hill, MA: TIMSS \& PIRLS International Study Center, Boston College.

Ifenthaler, D., \& Tracey, M. W. (2016). Exploring the relationship of ethics and privacy in learning analytics and design: implications for the field of educational technology. Educational Technology Research and Development, 64(5), 877-880.

Ingle, W. K., \& Cramer, T. (2013). 'Not Just Accountability: A Cost-Effectiveness Analysis of ThirdGrade Reading Diagnostic Tools'. In B. G. Barnett, A. R. Shoho \& A. J. Bowers (Eds.), School and district leadership in an era of accountability (pp. 143-171). Charlotte, NC: Information Age Publishing Inc.

Jacobs, J., Gregory, A., Hoppey, D., \& YendolHoppey, D. (2009). 'Data Literacy: Understanding Teachers' Data Use in a Context of Accountability and Response to Intervention'. Action in Teacher Education, 31(3), 41-55. 
Jimerson, J. B., \& Childs, J. (in press). Signal and Symbol: How State and Local Policies Address DataInformed Practice. Educational Policy.

Jimerson, J. B., \& Wayman, J. C. (2015). 'Professional Learning for Using Data: Examining Teacher Needs and Supports'. Teachers College Record, 117(4), 1-36.

Jürges, H., Schneider, K., \& Büchel, F. (2005). 'The effect of central exit examinations on student achievement: Quasi-experimental evidence from TIMSS Germany'. Journal of the European Economic Association, 3(5), 1134-1155.

Kickmeier-Rust, M. D., \& Albert, D. (2013). 'Learning analytics to support the use of virtual worlds in the classroom'. In Human-Computer Interaction and Knowledge Discovery in Complex, Unstructured, Big Data (pp. 358-365). Springer Berlin Heidelberg.

Kirkup, C., Sizmur, J., Sturman, L., \& Lewis, K. (2005). 'Schools' Use of Data in Teaching and Learning'. Research Report RR671. National Foundation for Educational Research.

Knowles, J. E. (2015). 'Of Needles and Haystacks: Building an Accurate Statewide Dropout Early Warning System in Wisconsin'. Journal of Educational Data Mining, 7(3), 18-67.

Koedinger, K. R., Baker, R. S., Cunningham, K., Skogsholm, A., Leber, B., \& Stamper, J. (2010). 'A data repository for the EDM community: The PSLC DataShop'. In C. Romero, S. Ventura, M. Penchenizkiy \& R. S. Baker (Eds.), Handbook of Educational Data Mining (pp. 43-55).

Koedinger, K. R., D'Mello, S., McLaughlin, E. A., Pardos, Z. A., \& Rosé, C. P. (2015). 'Data mining and education'. Wiley Interdisciplinary Reviews: Cognitive Science, 6(4), 333-353.

Koon, S., \& Petscher, Y. (2015). 'Comparing Methodologies for Developing an Early Warning System: Classification and Regression Tree Model versus Logistic Regression'. REL 2015-077. Regional Educational Laboratory Southeast.

Laurillard, D. (2008). 'The teacher as action researcher: Using technology to capture pedagogic form'. Studies in Higher Education, 33(2), 139-154.

Lawson, C., Beer, C., Rossi, D., Moore, T., \& Fleming, J. (2016). Identification of 'at risk' students using learning analytics: the ethical dilemmas of intervention strategies in a higher education institution. Educational Technology Research and Development, 64(5), 957-968.
Leithwood, K. (2013). 'Concluding synthesis and commentary'. In B. G. Barnett, A. R. Shoho \& A. J. Bowers (Eds.), School and district leadership in an era of accountability (pp. 255-269). Charlotte, NC: Information Age Publishing Inc.

Levin, H. M., Belfield, C. R., Hollands, F., Bowden, A. B., Cheng, H., Shand, R., Hanisch-Cerda, B. (2012). 'Cost-effectiveness analysis of interventions that improve high school completion'. New York, NY: Center for Benefit-Cost Studies of Education, Teachers College, Columbia University.

Lovenheim, M. F., \& Walsh, P. (2014). 'Does Choice Increase Information? Evidence from Online School Search Behavior', paper presented at the 2016 AEFP Conference.

Mac Iver, M. A. (2013). 'Early Warning Indicators of High School Outcomes'. Journal of Education for Students Placed at Risk (JESPAR), 18(1), 1-6.

Macfadyen, L. P., \& Dawson, S. (2012). 'Numbers Are Not Enough. Why e-Learning Analytics Failed to Inform an Institutional Strategic Plan'. Educational Technology \& Society, 15(3), 149-163.

Macfadyen, L. P., Dawson, S., Pardo, A., \& Gasevic, D. (2014). 'Embracing big data in complex educational systems: The learning analytics imperative and the policy challenge'. Research \& Practice in Assessment, 9.

Mandinach, E. B., \& Gummer, E. S. (2013). 'A Systemic View of Implementing Data Literacy in Educator Preparation'. Educational Researcher, 42(1), 30-37.

Mandinach, E. B., Honey, M., \& Light, D. (2006). 'A Theoretical Framework for Data-Driven Decision Making', Paper presented at the American Educational Research Association, San Francisco, CA

Mandinach, E. B., Honey, M., Light, D., \& Brunner, C. (2008). 'A Conceptual Framework for Data-Driven Decision Making'. In E. B. Mandinach \& M. Honey (Eds.), Data-Driven School Improvement: Linking Data and Learning (pp. 13-31). New York: Teachers College Press.

Marsh, J. A. (2012). 'Interventions Promoting Educators' Use of Data: Research Insights and Gaps'. Teachers College Record, 114(11), 1-48.

Marsh, J. A., \& Farrell, C. C. (2015). How leaders can support teachers with data-driven decision making: A framework for understanding capacity building. Educational Management Administration \& Leadership, 43(2), 269-289. 
Marsh, J. A., Pane, J. F., \& Hamilton, L. S. (2006). 'Making sense of data-driven decision making in education', RAND Corporation Occasional Paper.

Masum, H., Rao, A., Good, B. M., Todd, M. H., Edwards, A. M., Chan, L., Bourne, P. E. (2013). 'Ten Simple Rules for Cultivating Open Science and Collaborative R\&D'. PLos Computational Biology, 9(9).

Means, B., Padilla, C., \& Gallagher, L. (2010). 'Use of Education Data at the Local Level From Accountability to Instructional Improvement'. Washington, DC: U.S. Department of Education, Office of Planning, Evaluation and Policy Development.

Meyer, H. D., \& Benavot, A. (Eds.). (2013). PISA, power, and policy: The emergence of global educational governance. Symposium Books Ltd.

Mockler, N. (2013). 'Reporting the 'education revolution': MySchool. edu. au in the print media'. Discourse: Studies in the Cultural Politics of Education, 34(1), 1-16.

Molloy, J. C. (2011). 'The Open Knowledge Foundation: Open Data Means Better Science'. PLos Biology, 9(12).

Mosteller, F., \& Boruch, R. F. (Eds.). (2002). Evidence matters: Randomized trials in education research. Brookings Institution Press.

Murnane, R. J. (2013). 'US high school graduation rates: Patterns and explanations' (No. w18701). National Bureau of Economic Research.

Murray, J. (2013). 'Critical issues facing school leaders concerning data-informed decision-making'. School Leadership \& Management, 33(2), 169-177.

Ni, X., Bowers, A. J., \& Essewein, J. (2016). 'What Counts in Calculating School and District Level Performance Index Scores: A Summary and Analysis of Academic Performance Index Metrics across the 50 States'. New York: Teachers College, Columbia University.

Pardo, A., \& Siemens, G. (2014). 'Ethical and privacy principles for learning analytics'. British Journal of Educational Technology, 45(3), 438-450.

Piety, P. J. (2013). Assessing the educational data movement. New York, NY: Teachers College Press.

Popham, W. J. (2010). Everything school leaders need to know about assessment. Thousand Oaks, CA: Corwin.

Agasisti \& Bowers (2017)
Raghupathi, W., \& Raghupathi, V. (2014). 'Big data analytics in healthcare: promise and potential'. Health Information Science and Systems, 2(1), 3.

Reeves, P. L., \& Burt, W. L. (2006). 'Challenges in Data-Based Decision-Making: Voices from Principals'. Educational Horizons, 85(1), 65-71.

Riehl, C. (1999). 'Labeling and letting go: An organizational analysis of how high school students are discharged as dropouts'. In A. M. Pallas (Ed.), Research in sociology of education and socialization (pp. 231-268). New York: JAI Press.

Romero, C., \& Ventura, S. (2007). 'Educational data mining: A survey from 1995 to 2005'. Expert systems with applications, 33(1), 135-146.

Romero, C., \& Ventura, S. (2010). 'Educational data mining: a review of the state of the art'. Systems, Man, and Cybernetics, Part C: Applications and Reviews, IEEE Transactions on, 40(6), 601-618.

Rumberger, R. W., \& Palardy, G. J. (2005). 'Test scores, dropout rates, and transfer rates as alternative indicators of high school performance'. American Educational Research Journal, 42(1), 3-42.

Rutledge, S., \& Gale Neal, B. (2013). "The numbers speak for themselves": Data use and organization of schooling in two Florida elementary schools' in The infrastructure of accountability: Data use and the transformation of American education (pp. 113-128). Cambridge, Mass: Harvard Education Press.

Scheuer, O., \& McLaren, B. M. (2012). 'Educational data mining'. In Encyclopedia of the Sciences of Learning (pp. 1075-1079). Springer US.

Schildkamp, K., Karbautzki, L., \& Vanhoof, J. (2014). Exploring data use practices around Europe: Identifying enablers and barriers. Studies in Educational Evaluation, $42,15-24$.

Schildkamp, K., Poortman, C. L., \& Handelzalts, A. (2016). 'Data teams for school improvement'. School Effectiveness and School Improvement, 27(2), 228-254.

Schildkamp, K., Poortman, C., Luyten, H., \& Ebbeler, J. (in press). Factors promoting and hindering data-based decision making in schools. School Effectiveness and School Improvement, 1-17.

Schleicher, A. (2016). 'Going beyond education policies - how can PISA help turn policy into practice?' Education \& Skills Today, OECD.

Schneider, B., Carnoy, M., Kilpatrick, J., Schmidt, W. H., \& Shavelson, R. J. (2007). 'Estimating casual effects: 
Using experimental and observational designs' (report from the Governing Board of the American Educational Research Association Grants Program). Washington, DC: American Educational Research Association.

Schmidt, W. H., McKnight, C. C., Houang, R. T., Wang, H., Wiley, D. E., Cogan, L. S., \& Wolfe, R. G. (2001). Why Schools Matter: A Cross-National Comparison of Curriculum and Learning. The Jossey-Bass Education Series. Jossey-Bass, 989 Market Street, San Francisco, CA 94103-1741.

Scholes, V. (2016). The ethics of using learning analytics to categorize students on risk. Educational Technology Research and Development, 64(5), 939-955.

Schutt, R., \& O'Neil, C. (2013). Doing Data Science: Straight Talk from the Frontline. Cambridge, MA: O'Reilly.

Siemens, G. (2010). 'What are learning analytics'. ELEARNSPACE: Learning, networks, knowledge, technology, community.

Siemens, G. (2013). 'Learning Analytics: the emergence of a Discipline'. American Behavioral Scientist, 57(10), 1380-1400.

Siemens, G., \& Long, P. (2011). 'Penetrating the Fog: Analytics in Learning and Education'. EDUCAUSE review, 46(5), 30.

Slade, S., \& Prinsloo, P. (2013). 'Learning analytics ethical issues and dilemmas'. American Behavioral Scientist, 57(10), 1510-1529.

Slavin, R. E. (2002). 'Evidence-based education policies: Transforming educational practice and research'. Educational Researcher, 31(7), 15-21.

Stodden, V., Guo, P., \& Ma, Z. (2013). Toward Reproducible Computational Research: An Empirical Analysis of Data and Code Policy Adoption by Journals. PloS one, 8(6), e67111.

Spector, J. M. (2016). Ethics in educational technology: towards a framework for ethical decision making in and for the discipline. Educational Technology Research and Development, 64(5), 1003-1011

Strasser, C. (2015). Research Data Management. Baltimore, MD: National Information Standards Organization.

Strietholt, R., Bos, W., Gustafsson, J. E., \& Rosén, M. (Eds.). (2014). Educational Policy Evaluation through International Comparative Assessments. Waxmann Verlag.

Agasisti \& Bowers (2017)
Tibshirani, R. (1996). 'Regression shrinkage and selection via the lasso'. Journal of the Royal Statistical Society. Series B (Methodological), 267-288.

Turner, E. O., \& Coburn, C. E. (2012). 'Interventions to promote data use: An introduction'. Teachers College Record, 114(11), 1-13.

Verbert, K., Duval, E., Klerkx, J., Govaerts, S., \& Santos, J. L. (2013). 'Learning analytics dashboard applications'. American Behavioral Scientist, 57(10), 1500-1509.

Wayman, J. C. (2005). 'Involving teachers in datadriven decision making: Using computer data systems to support teacher inquiry and reflection'. Journal of Education for Students Placed at Risk, 10(3), 295-308.

Wayman, J. C., Stringfield, S., \& Yakimowski, M. (2004). 'Software enabling school improvement through the analysis of student data' (Report No. 67). Baltimore, MD: Johns Hopkins University, Center for Researc on the Education of Students Placed At Risk.

Wayman, J. C., \& Stringfield, S. (2006). 'Data use for school improvement: School practices and research perspectives'. American Journal of Education, 112(4), 463-468.

Wayman, J. C., Cho, V., \& Johnston, M. T. (2007). 'The data-informed district: A district-wide evaluation of data use in the Natrona county school district'. Austin: The University of Texas at Austin.

Wayman, J. C., Cho, V., Jimerson, J. B., \& Snodgrass Rangel, V. W. (2015). 'A Look into the Workings of Data Use in a Mid-Sized District'. In I. E. Sutherland, K. L. Sanzo \& J. P. Scribner (Eds.), Leading Small and MidSized Urban School Districts (Vol. 22, pp. 241-275): Emerald.

Wayman, J. C., Cho, V., Jimerson, J. B., \& Spikes, D. D. (2012). 'District-wide effects on data use in the classroom'. Education Policy Analysis Archives, 20(25), 128.

Whitty, G. (2006). 'Education(al) research and education policy making: is conflict inevitable?'. British Educational Research Journal, 32(2), 159-176.

Williamson, B. (2016). 'Digital education governance: data visualization, predictive analytics, and 'realtime'policy instruments'. Journal of Education Policy, 31(2), 123-141.

Willis III, J. E., Campbell, J., \& Pistilli, M. (2013). 'Ethics, Big Data, and Analytics: A Model for Application', EDUCAUSE Review Online. 
Willis, J. E., Slade, S., \& Prinsloo, P. (2016). Ethical oversight of student data in learning analytics: a typology derived from a cross-continental, cross-institutional perspective. Educational Technology Research and Development, 64(5), 881-901.

Woessmann, L. (2008). 'Efficiency and equity of European education and training policies'. International Tax and Public Finance, 15(2), 199-230.

Woessmann, L., \& West, M. (2006). 'Class-size effects in school systems around the world: Evidence from between-grade variation in TIMSS'. European Economic Review, 50(3), 695-736.

Yang, M., Goldstein, H., Rath, T., \& Hill, N. (1999). 'The use of assessment data for school improvement purposes'. Oxford Review of Education, 25(4), 469-483.

Yiu, C. (2012). 'The big data opportunity: Making government faster, smarter and more personal'. Policy Exchange.

Yoon, S. Y. (in press). Principals' Data-Driven Practice and Its Influences on Teacher Buy-in and Student Achievement in Comprehensive School Reform Models. Leadership and Policy in Schools, 1-24. 